Rev. Bras. Saúde Prod. Anim., Salvador, v.13, n.2, p.424-432 abr./jun., 2012 http://www.rbspa.ufba.br ISSN 15199940

\title{
Cinética de degradação de frações nutricionais de euforbiáceas
}

\author{
Kinects of degradation in nutritional fractions of euphorbiaceous
}

\author{
MENEZES, Daniel Ribeiro ${ }^{1 *}$; PEREIRA, Luiz Gustavo Ribeiro²; ARAÚJO, Gherman \\ Garcia Leal de ${ }^{3}$; CHAGAS, Ellio Celestino de Oliveira ${ }^{4}$; RODRIGUES, Rafael Torres \\ de Souza ${ }^{5}$, SILVA, Thadeu Mariniello ${ }^{6}$
}

\footnotetext{
${ }^{1}$ Universidade Federal do Vale do São Francisco, Campus de Ciências Agrárias, Colegiado Acadêmico de Medicina Veterinária, Petrolina, Pernambuco, Brasil.

${ }^{2}$ Embrapa Gado de Leite, Centro Nacional de Pesquisa em Gado de Leite, Juiz de Fora, Minas Gerais, Brasil.

${ }^{3}$ Embrapa Semiárido, Centro de Pesquisa Agropecuária do Trópico Semiárido, Setor de Nutrição Animal, Petrolina, Pernambuco, Brasil.

${ }^{4}$ Instituto Federal de Educação, Ciência e Tecnologia Pernambucano, Petrolina, Pernambuco, Brasil.

${ }^{5}$ Universidade Federal do Vale do São Francisco, Campus de Ciências Agrárias, Programa de PósGraduação em Ciência Animal, Petrolina, Pernambuco, Brasil.

${ }^{6}$ Universidade Federal da Bahia, Bolsista de Pós Doutorado CNPq, Salvador, Bahia, Brasil.

*Endereço para correspondência: daniel.menezes@univasf.edu.br
}

\section{RESUMO}

Objetivou-se determinar a composição e a degradabilidade in situ da matéria seca, proteína bruta e fibra em detergente neutro dos fenos da mamona Paraguaçu (Ricinus communis), da mamona Nordestina (Ricinus communis), do pinhão manso (Jatropha curcas) e da maniçoba (Manihot pseudoglaziovii). Utilizaram-se três ovinos sem raça definida fistulados no rúmen. Em cada animal foram incubados 12 sacos nos períodos de 6; 12; 24; 48 e 96 horas, sendo três por feno de euforbiácea. $\mathrm{O}$ teor proteico variou entre $10,3 \%$ para o feno de pinhão manso e $19,6 \%$ para o feno da maniçoba. O valor de fibra em detergente neutro foi semelhante entre os fenos do pinhão manso e da maniçoba, enquanto os fenos das mamonas, apresentaram valores inferiores às anteriores e semelhantes entre si. $\mathrm{O}$ feno da mamona Paraguaçu obteve maior e mais rápida degradação da matéria seca, com valor de $85,5 \%$, estagnado em 44 horas. Os fenos da maniçoba e do pinhão manso apresentaram degradação da proteína bruta semelhantes com valores final de $92,5 \%$ em 40 e 46 horas, respectivamente. $\mathrm{O}$ feno do pinhão manso obteve degradação da fibra em detergente neutro de $68,0 \%$ e foi superior aos fenos das outras euforbiáceas, porém, apresentou taxa de degradação mais lenta, estabilizada em 86 horas. Os fenos das mamonas foram superiores aos fenos das demais euforbiáceas em relação à composição bromatológica, aos coeficientes de degradação ruminal e a degradação potencial e efetiva dos nutrientes.

Palavras-chave: alimentos, biodiesel, fenação, fermentação ruminal

\section{SUMMARY}

In order to determine the composition and the in situ degradability of the dry matter, crude protein and neutral detergent fiber of hays of castor cv. Paraguaçu (Ricinus communis), castor cv. Nordestina (Ricinus communis), jatropha (Jatropha curcas) and maniçoba (Manihot pseudoglaziovii). Three rumen canulated undefined breed sheep were used. In each animal were incubated 12 bags for $6 ; 12 ; 24 ; 48$ and 96 hour, being three bags by hay of euphorbiaceae. The content of protein ranged between $10.3 \%$ for the hay of jatropha and $19.6 \%$ for the hay of maniçoba. The neutral detergent fiber value was similar between the hay of jatropha and the hay of maniçoba, while the hays of castors presented lower concentrations between themselves. The castor Paraguaçu hay presented superior and faster dry matter degradation, with value of $85.5 \%$ 
stagnated at 44 hour. The hay of maniçoba and the hay of jatropha showed similar degradability of crude protein with final valor of $92.5 \%$ degraded at 40 and 46 hour, respectively. The jatropha hay presented neutral detergent fiber degradation of $68.0 \%$ and was superior to other euphorbiaceous hay, but- showed slower degradation rate, stagnated at 86 hour. The hays of castors were superior to the other hays of euphorbiaceous for chemical composition, the coefficients of ruminal degradation and the potential and effective degradation of nutrients.

Keywords: biodiesel, feedstuffs, haying, rumen fermentation

\section{INTRODUÇÃO}

A produtividade animal no semiárido nordestino é deficiente devido à sazonalidade da disponibilidade e qualidade nutritiva das forragens presentes na região. Este panorama retrata a necessidade de incluir nas dietas dos animais alimentos alternativos com características nutritivas que supram tais deficiências (GOMES et al., 2009; LOUSADA JÚNIOR et al., 2005; MORAES \& VASCONCELOS, 2007).

A produção de biodiesel a partir do beneficiamento de oleaginosas mostrase promissora na região nordestina, e as euforbiáceas se destacam entre as mais cultivadas para este fim. Com isso, a quantidade crescente dessas plantas acarretará em excedentes que podem ser utilizados na alimentação animal. Entretanto, o conhecimento de seu teor de nutrientes, e a capacidade destes em serem utilizados pelos ruminantes ainda não é muito embasado (FREITAS \& FREDO, 2005).

Por meio da avaliação da composição e valor nutritivo dos alimentos é possível prever a utilização metabólica destes pelos ruminantes. Entretanto, esses valores não são tão precisos devido à necessidade de conhecimento das interações entre esses nutrientes nos alimentos, e do alimento como um todo, quando em contato com o sistema digestivo do ruminante (TOMICH et al., 2003).

A cinética da degradação ruminal tem sido pesquisada em diferentes alimentos utilizados na nutrição de ruminantes. Este fato tem se mostrado muito útil para os pesquisadores por contribuir com o balanceamento das dietas $\mathrm{e}$ atender as exigências dos microorganismos e do animal hospedeiro (CARVALHO et al., 2006a).

Para a avaliação da degradabilidade ruminal, a técnica do saco de náilon (in situ) suspenso no rúmen tem se apresentado como alternativa viável, principalmente em função de sua simplicidade, confiabilidade e baixo custo (ØRSKOV\& McDONALD, 1979).

Objetivou-se com este trabalho determinar a composição químicobromatológica e a degradabilidade in situ da matéria seca, proteína bruta e fibra em detergente neutro dos fenos da parte aérea oriunda das podas da mamona Paraguaçu (Ricinus communis), da mamona Nordestina (Ricinus communis), do pinhão manso (Jatropha curcas) e da maniçoba (Manihot pseudoglaziovii).

\section{MATERIAL E MÉTODOS}

O experimento foi conduzido no Laboratório de Nutrição Animal da Embrapa Semiárido.

Foram utilizados três ovinos SRD com peso vivo médio de $40 \mathrm{~kg}$, castrados e fistulados no rúmen. Os animais receberam dietas que atendiam às recomendações para ovinos em mantença na mesma faixa de peso (NRC, 2007) e foram compostas por feno de tifton, farelo de soja e farelo de milho.

Foram utilizadas as folhas e o terço superior provenientes das podas das 
plantas, que posteriormente, foram trituradas em máquina forrageira, obtendo partículas com tamanho de $5 \mathrm{~cm}$ de diâmetro, e em seguida foram submetidas ao processo de fenação sobre área cimentada ao sol durante dois dias.

As amostras foram pré-secas em estufa a $65^{\circ} \mathrm{C}$ por 72 horas, moídas em peneira de $5 \mathrm{~mm}$ e colocadas em sacos de náilon $(6 \times 10 \mathrm{~cm})$, com porosidade de $50 \mu$, em uma quantidade de aproximadamente 1,2 gramas de amostra por saco, o que representou $20 \mathrm{mg}$ de amostra $\mathrm{cm}^{-2} \mathrm{de}$ área do saco. Em cada animal foram incubados 12 sacos nos períodos de 6; 12; $24 ; 48$ e $96 \mathrm{~h}$, sendo três por feno de euforbiácea testada. $\mathrm{O}$ período zero foi obtido com a imersão dos sacos em água destilada a $37^{\circ} \mathrm{C}$ por 5 minutos. As incubações foram realizadas antes do fornecimento da dieta base. Após este período, os sacos foram retirados $\mathrm{e}$ colocados em balde com água gelada para interromper a ação microbiana, lavados em água corrente até que esta se apresentasse limpa, e procedeu-se então à secagem em estufa a $65^{\circ} \mathrm{C}$ por $72 \mathrm{~h}$.

As análises químico-bromatológicas foram realizadas segundo metodologia descrita por Silva \& Queiroz (2002). Para a determinação da degradabilidade potencial foi utilizado o modelo de Ørskov \& Mcdonald (1979):

$\mathrm{DP}=\mathrm{a}+\mathrm{b}\left(1-\mathrm{e}^{-\mathrm{ct}}\right)$, em que "DP" é a degradabilidade potencial; "a" a fração solúvel em água; "b" a fração insolúvel em água, mas potencialmente degradável; "c" a taxa de degradação da fração (b); e " $t$ " o tempo de incubação em horas. A letra "e" é o log natural de (-ct). A degradabilidade efetiva (DE) foi calculada pela fórmula: $\mathrm{DE}=\mathrm{a}+(\mathrm{b} \times \mathrm{c})$ / $(c+k)$, em que " $k$ " é a taxa de passagem. $\mathrm{O}$ delineamento experimental utilizado foi o de parcelas subdivididas, em que os três animais representaram os blocos; as quatro forragens, os tratamentos; e os seis tempos de incubação dos alimentos no rúmen, as subparcelas.

Foi desenvolvida análise de variância e aplicado o teste de Tukey a 5\% de probabilidade para comparar as médias de degradabilidade testadas de acordo com os períodos de incubação mediante utilização do programa estatístico Statistical Analysis Sytems (SAS INSTITUTE, 2003).

\section{RESULTADOS E DISCUSSÃO}

Na composição bromatológica dos fenos das euforbiáceas é possivel compará-los com resultados obtidos com o guandu (PIRES et al., 2006), leguminosa que apresenta aproximadamente $22 \%$ de proteína bruta $(\mathrm{PB})$ e é muito utilizada como banco de proteína para ruminantes (Tabela 1).

A PB do feno de pinhão manso apresenta em sua constituição $30,7 \%$ de proteína insolúvel em detergente neutro (PIDN), composto com reduzida capacidade de fermentação, o que pode gerar baixa disponibilidade desta fração proteíca para os ruminantes. Aliado a isto, o teor de lignina (LIG) desta forragem é considerado alto (14,8\%), o que poderia indisponibilizar ainda mais os seus nutrientes.

Não foi observada diferença na solubilidade ou desaparecimento da MS no tempo zero de incubação dos fenos das euforbiáceas, que obtiveram valor médio de $14,7 \%$. Observaram-se valores semelhantes de desaparecimento da MS para os fenos da mamona Paraguaçu, do pinhão manso e da mamona Nordestina, que foram superiores ao feno da maniçoba a partir de 12 horas de incubação (Tabela 2).

Em relação ao desaparecimento da MS por tempo de incubação, observou-se que os valores do feno da mamona Paraguaçu 
Rev. Bras. Saúde Prod. Anim., Salvador, v.13, n.2, p.424-432 abr./jun., 2012 http://www.rbspa.ufba.br ISSN 15199940

estabilizaram a partir de 12 horas de incubação. Este comportamento para o feno da mamona Paraguaçu é importante, pois, a rápida e extensa degradação ruminal da MS está relacionada com maiores valores de consumo pelos animais, devido ao maior esvaziamento do rúmen (TOMICH et al., 2003). Para os demais fenos de euforbiáceas não ocorreram diferenças nos tempos de 24 a 96 horas de incubação (Tabela 2).

Tabela 1. Composição bromatológica dos fenos das euforbiáceas em porcentagem (\%)

\begin{tabular}{|c|c|c|c|c|}
\hline \multirow[b]{2}{*}{ Parâmetros } & \multicolumn{4}{|c|}{ Euforbiáceas } \\
\hline & $\begin{array}{l}\text { Pinhão } \\
\text { manso }\end{array}$ & $\begin{array}{c}\text { Mamona } \\
\text { Nordestina }\end{array}$ & $\begin{array}{c}\text { Mamona } \\
\text { Paraguaçu }\end{array}$ & Maniçoba \\
\hline Matéria seca \% & 87,6 & 89,4 & 89,8 & 89,8 \\
\hline Matéria orgânica* & 85,1 & 92,1 & 91,8 & 91,8 \\
\hline Proteína bruta* & 10,3 & 19,5 & 17,5 & 19,6 \\
\hline Extrato etéreo* & 2,1 & 2,4 & 2,5 & 2,2 \\
\hline Fibra em detergente neutro* & 34,5 & 27,4 & 30,1 & 35,5 \\
\hline Fibra em detergente ácido* & 25,7 & 22,9 & 22,9 & 27,9 \\
\hline $\begin{array}{l}\text { Proteína insolúvel em detergente } \\
\text { neutro** }\end{array}$ & 30,7 & 13,0 & 11,9 & 15,8 \\
\hline $\begin{array}{l}\text { Proteína insolúvel em detergente } \\
\text { ácido** }\end{array}$ & 14,8 & 10,7 & 8,1 & 5,6 \\
\hline Lignina* & 14,8 & 5,3 & 4,7 & 9,3 \\
\hline $\begin{array}{l}\text { Nutrientes digestíveis totais } \\
{ }^{1} \text { est.* }\end{array}$ & 64,9 & 74,9 & 76,2 & 68,7 \\
\hline
\end{tabular}

Tabela 2. Desaparecimento médio (\%) da matéria seca dos fenos de euforbiáceas no tempo zero e em diferentes tempos de incubação ruminal em ovinos

\begin{tabular}{lcccc}
\hline Tempos (h) & Pinhão manso & $\begin{array}{c}\text { Mamona } \\
\text { Paraguaçu }\end{array}$ & $\begin{array}{c}\text { Mamona } \\
\text { Nordestina }\end{array}$ & Maniçoba \\
\hline 0 & $14,00^{\mathrm{aA}}$ & $15,81^{\mathrm{aA}}$ & $15,41^{\mathrm{aA}}$ & $14,62^{\mathrm{aA}}$ \\
6 & $51,34^{\mathrm{aB}}$ & $66,34^{\mathrm{bB}}$ & $62,29^{\mathrm{bB}}$ & $50,37^{\mathrm{aB}}$ \\
12 & $73,02^{\mathrm{bC}}$ & $81,51^{\mathrm{bC}}$ & $75,94^{\mathrm{bC}}$ & $61,85^{\mathrm{aC}}$ \\
24 & $83,07^{\mathrm{bD}}$ & $87,69^{\mathrm{bC}}$ & $86,35^{\mathrm{bD}}$ & $68,67^{\mathrm{aD}}$ \\
48 & $86,45^{\mathrm{bD}}$ & $86,42^{\mathrm{bC}}$ & $84,75^{\mathrm{bD}}$ & $70,77^{\mathrm{aD}}$ \\
96 & $83,06^{\mathrm{bD}}$ & $81,81^{\mathrm{bC}}$ & $82,42^{\mathrm{bD}}$ & $69,44^{\mathrm{aD}}$ \\
\hline
\end{tabular}

Letras minúsculas na mesma linha e letras maiúsculas na mesma coluna diferentes conferem diferença estatística a $5 \%$ de probabilidade pelo teste Tukey.

Os fenos das euforbiáceas apresentaram valores semelhantes $(\mathrm{p}<0,05)$ de solubilidade ou desaparecimento da $\mathrm{PB}$ no tempo zero de incubação ruminal, que geraram valor médio de $18,5 \%$. A taxa e a extensão de desaparecimento da PB dos fenos das mamonas foram significativamente maiores, comparadas 
Rev. Bras. Saúde Prod. Anim., Salvador, v.13, n.2, p.424-432 abr./jun., 2012 http://www.rbspa.ufba.br ISSN 15199940

aos fenos do pinhão manso e da maniçoba, apresentando mais de $90 \%$ de desaparecimento com 12 horas de incubação (Tabela 3).

A disponibilidade de PB degradável no rúmen é uma característica importante do alimento, necessária à síntese de proteína microbiana, que é a principal fonte de proteína metabolizável para o ruminante (SILVA et al., 2002).

Tabela 3. Desaparecimento médio (\%) da proteína bruta dos fenos de euforbiáceas no tempo zero e em diferentes tempos de incubação ruminal em ovinos

\begin{tabular}{lcccc}
\hline Tempos (h) & Pinhão manso & $\begin{array}{c}\text { Mamona } \\
\text { Paraguaçu }\end{array}$ & $\begin{array}{c}\text { Mamona } \\
\text { Nordestina }\end{array}$ & Maniçoba \\
\hline 0 & $16,50^{\mathrm{aA}}$ & $18,50^{\mathrm{aA}}$ & $18,92^{\mathrm{aA}}$ & $20,10^{\mathrm{aA}}$ \\
6 & $72,34^{\mathrm{aB}}$ & $83,38^{\mathrm{bB}}$ & $88,67^{\mathrm{bB}}$ & $75,89^{\mathrm{aB}}$ \\
12 & $85,51^{\mathrm{aC}}$ & $96,30^{\mathrm{bC}}$ & $95,79^{\mathrm{bC}}$ & $87,79^{\mathrm{CC}}$ \\
24 & $92,52^{\mathrm{bD}}$ & $97,69^{\mathrm{cC}}$ & $97,46^{\mathrm{cC}}$ & $88,36^{\mathrm{aC}}$ \\
48 & $94,25^{\mathrm{aD}}$ & $97,37^{\mathrm{aC}}$ & $97,07^{\mathrm{aC}}$ & $94,15^{\mathrm{aD}}$ \\
96 & $91,09^{\mathrm{aD}}$ & $95,79^{\mathrm{aC}}$ & $96,63^{\mathrm{aC}}$ & $94,06^{\mathrm{aD}}$ \\
\hline
\end{tabular}

Letras minúsculas na mesma linha e letras maiúsculas na mesma coluna diferentes conferem diferença estatística a $5 \%$ de probabilidade pelo teste Tukey.

Não foram observadas diferenças significativas na solubilidade ou desaparecimento da FDN no tempo zero de incubação entre os fenos das euforbiáceas, que tiveram média de $9,5 \%$. $\mathrm{O}$ feno do pinhão manso teve a maior extensão de desaparecimento da FDN, apresentando valor máximo de $72,46 \%$ com 48 horas de incubação. Por outro lado, o feno da maniçoba teve o menor desaparecimento da FDN, apresentando valor máximo de $45,75 \%$ com 96 horas de incubação, porém, foi superior ao valor máximo descrito por França et al. (2010) para o feno de maniçoba que foi de 26,72\% com 96 horas de incubação. O feno da mamona Paraguaçu foi superior ao feno da mamona Nordestina, apresentando maior desaparecimento da FDN (Tabela 4).

Tabela 4. Desaparecimento médio (\%) da fibra em detergente neutro dos fenos de euforbiáceas no tempo zero e em diferentes tempos de incubação ruminal em ovinos

\begin{tabular}{lcccc}
\hline Tempos (h) & Pinhão manso & $\begin{array}{c}\text { Mamona } \\
\text { Paraguaçu }\end{array}$ & $\begin{array}{c}\text { Mamona } \\
\text { Nordestina }\end{array}$ & \begin{tabular}{c} 
Maniçoba \\
\hline 0
\end{tabular} \\
$10,10^{\mathrm{aA}}$ & $10,00^{\mathrm{aA}}$ & $8,80^{\mathrm{aA}}$ & $9,10^{\mathrm{aA}}$ \\
6 & $30,57^{\mathrm{bB}}$ & $31,81^{\mathrm{bB}}$ & $24,69^{\mathrm{aB}}$ & $32,19^{\mathrm{bB}}$ \\
12 & $53,67^{\mathrm{bC}}$ & $55,08^{\mathrm{bC}}$ & $35,97^{\mathrm{aC}}$ & $38,93^{\mathrm{aBC}}$ \\
24 & $65,83^{\mathrm{bD}}$ & $64,37^{\mathrm{bC}}$ & $55,66^{\mathrm{bD}}$ & $39,45^{\mathrm{aBC}}$ \\
48 & $72,46^{\mathrm{cD}}$ & $61,75^{\mathrm{bC}}$ & $48,48^{\mathrm{aD}}$ & $42,56^{\mathrm{aCD}}$ \\
96 & $62,94^{\mathrm{cD}}$ & $58,44^{\mathrm{bC}}$ & $50,51^{\mathrm{bD}}$ & $45,75^{\mathrm{aD}}$ \\
\hline
\end{tabular}

Letras minúsculas na mesma linha e letras maiúsculas na mesma coluna diferentes conferem diferença estatística a $5 \%$ de probabilidade pelo teste Tukey. 
Rev. Bras. Saúde Prod. Anim., Salvador, v.13, n.2, p.424-432 abr./jun., 2012 http://www.rbspa.ufba.br ISSN 15199940

Os valores das frações da MS solúvel em água (a) dos fenos das euforbiáceas estudadas foram superiores a 5,4\% encontrado por Carvalho et al. (2006b) na análise de degradação do feno da parte aérea da mandioca. Quanto à fração (b) da MS, o feno da maniçoba obteve menor valor $(55,3 \%)$ comparado aos outros fenos, enquanto o feno do pinhão manso obteve o maior valor $(71,1 \%)$ para este coeficiente. Por outro lado, o feno do pinhão manso apresentou a menor taxa de degradação (c) desta fração da MS $(0,14 \% / \mathrm{h})$. A maior taxa de degradação (c) da fração (b) da MS foi obtida pelo feno da mamona Paraguaçu $(0,22 \% / h)$. França et al. (2010) descreveram os seguintes valores para os coeficientes $(a, b$ e c) da degradação da MS do feno de maniçoba, 27,$47 ; 30,52$ e $5,35 \% / \mathrm{h}$, respectivamente.

Os fenos das mamonas Paraguaçu e Nordestina possuíram frações da PB solúveis em água (a) semelhantes, enquanto o feno da maniçoba e do pinhão manso obtiveram valores extremos, sendo a maniçoba superior (Tabela 5). Este resultado pode ser explicado em função do feno do pinhão manso possuir maiores valores de PIDN (Tabela 1), que representa a fração proteica menos solúvel e fermentável.

Tabela 5. Coeficientes $(\mathrm{a}, \mathrm{b}, \mathrm{c})$, coeficientes de determinação $\left(\mathrm{R}^{2}\right)$, degradabilidade potencial (DP) e degradabilidade efetiva (DE) obtidos na matéria seca (MS), proteína bruta $(\mathrm{PB})$ e fibra em detergente neutro (FDN) dos fenos das euforbiáceas estudadas

\begin{tabular}{|c|c|c|c|c|c|c|c|c|}
\hline \multirow[t]{2}{*}{ Euforbiácea } & \multicolumn{4}{|c|}{ Coeficientes (MS) } & \multirow{2}{*}{ DP (MS) } & \multicolumn{3}{|c|}{$\mathrm{DE}(\mathrm{MS})$} \\
\hline & $\mathrm{a}(\%)$ & $\mathrm{b}(\%)$ & $\mathrm{c}(\% / \mathrm{h})$ & $\mathrm{R}^{2}$ & & $2,0 \% / \mathrm{h}$ & $5,0 \% / \mathrm{h}$ & $8,0 \% / \mathrm{h}$ \\
\hline P. manso & 13,5 & 71,1 & 0,14 & 0,99 & 84,6 & 75,7 & 65,9 & 58,7 \\
\hline M. Nordestina & 15,5 & 69,3 & 0,18 & 0,99 & 84,8 & 77,9 & 69,7 & 63,5 \\
\hline M. Paraguaçu & 15,7 & 69,8 & 0,22 & 0,99 & 85,5 & 79,7 & 72,6 & 66,9 \\
\hline Maniçoba & 14,7 & 55,3 & 0,17 & 0,99 & 70,0 & 64,2 & 57,4 & 52,3 \\
\hline \multirow[t]{2}{*}{ Euforbiácea } & \multicolumn{4}{|c|}{ Coeficientes (PB) } & \multirow{2}{*}{$\mathrm{DP}(\mathrm{PB})$} & \multicolumn{3}{|c|}{$\mathrm{DE}(\mathrm{PB})$} \\
\hline & $\mathrm{a}(\%)$ & $\mathrm{b}(\%)$ & $\mathrm{c}(\% / \mathrm{h})$ & $\mathrm{R}^{2}$ & & $2,0 \% / \mathrm{h}$ & $5,0 \% / \mathrm{h}$ & $8,0 \% / \mathrm{h}$ \\
\hline P. manso & 16,6 & 75,9 & 0,21 & 0,99 & 92,5 & 85,9 & 77,9 & 71,6 \\
\hline M. Nordestina & 18,9 & 78,1 & 0,37 & 0,99 & 97,0 & 93,0 & 87,7 & 83,1 \\
\hline M. Paraguaçu & 18,5 & 78,9 & 0,29 & 0,99 & 97,4 & 92,3 & 85,8 & 80,3 \\
\hline Maniçoba & 20,2 & 72,3 & 0,24 & 0,99 & 92,5 & 86,9 & 80,0 & 74,4 \\
\hline \multirow[t]{2}{*}{ Euforbiácea } & \multicolumn{4}{|c|}{ Coeficientes (FDN) } & \multirow{2}{*}{ DP (FDN) } & \multicolumn{3}{|c|}{$\mathrm{DE}(\mathrm{FDN})$} \\
\hline & $\mathrm{a}(\%)$ & $\mathrm{b}(\%)$ & $\mathrm{c}(\% / \mathrm{h})$ & $\mathrm{R}^{2}$ & & $2,0 \% / \mathrm{h}$ & $5,0 \% / \mathrm{h}$ & $8,0 \% / \mathrm{h}$ \\
\hline P. manso & 8,3 & 59,7 & 0,11 & 0,96 & 68,0 & 58,8 & 49,3 & 42,9 \\
\hline M. Nordestina & 6,6 & 46,4 & 0,10 & 0,95 & 53,0 & 45,3 & 37,5 & 32,4 \\
\hline M. Paraguaçu & 8,5 & 49,5 & 0,15 & 0,90 & 58,0 & 52,2 & 45,6 & 40,8 \\
\hline Maniçoba & 9,1 & 31,8 & 0,22 & 0,98 & 40,9 & 38,3 & 35,0 & 32,4 \\
\hline
\end{tabular}


Em relação à fração (b) da $\mathrm{PB}$, o feno da maniçoba apresenta menor coeficiente $(72,3 \%)$ em relação às outras euforbiáceas, porém, próximo a $74,2 \%$, valor encontrado por Carvalho et al. (2006b) quando analisou o feno da parte aérea da mandioca. $\mathrm{O}$ maior valor da fração (b) da PB foi para o feno da mamona Paraguaçu $(78,9 \%)$. O feno da mamona Nordestina apresentou a maior taxa de degradação (c) da fração (b) da $\mathrm{PB}$ entre os fenos estudados $(0,37 \% / \mathrm{h})$. O coeficiente (a) da FDN do feno da mamona Nordestina foi o menor valor obtido em relação aos outros fenos $(6,6 \%)$, que obtiveram valores semelhantes (Tabela 5).

Os fenos das mamonas possuíram valores similares da fração (b) da FDN, e o feno do pinhão manso o maior coeficiente $(59,7 \%)$. O feno da maniçoba apresentou o menor valor para a fração (b) da FDN $(31,8 \%)$, porém, esta é degradada mais rapidamente que nos outros fenos, fato evidenciado por meio da constatação dos coeficientes (c) da FDN apresentados na Tabela 5. Segundo TOMICH et al. (2003), a taxa de degradação da fibra de um alimento pelos micro-organismos é que rege sua permanência no rúmen, ou seja, quanto mais degradável for a FDN do alimento, mais rápida será sua passagem por esse compartimento e maior será seu consumo.

$\mathrm{O}$ feno da maniçoba apresentou a menor degradabilidade potencial (DP) da MS (Tabela 5), dentre os fenos das euforbiáceas testadas, porém foi superior a $57,1 \%$ obtido por Carvalho et al. (2006b) com o feno da parte aérea da mandioca. Os fenos do pinhão manso e da maniçoba apresentaram valores idênticos de DP da PB. Os fenos das mamonas obtiveram maiores resultados para esta variável (Tabela 5). Quanto a DP da FDN, pode-se evidenciar que o feno do pinhão manso apresentou valor superior comparado aos outros fenos de euforbiáceas estudadas, e o feno da maniçoba o menor valor (Tabela 5). Este se mostrou similar ao feno da parte aérea da mandioca, que obteve valor de $38,5 \%$ no experimento descrito por Carvalho et al. (2006b).

A degradabilidade ruminal pode ser superestimada quando não se considera a taxa de passagem do alimento pelo rúmen. Quando alimentos têm sua permanência reduzida neste préestômago, diminui também, a sua degradação pelos micro-organismos. A degradabilidade efetiva (DE) leva em consideração taxas de passagem distintas e, desta forma, estima porcentagens mais próximas à realidade.

A degradabilidade efetiva da matéria seca (DEMS) do feno da maniçoba foi inferior aos fenos das outras euforbiáceas. Os fenos das mamonas apresentaram os maiores valores de DEMS, sendo a mamona Paraguaçu superior a mamona Nordestina. O feno do pinhão manso apresentou valores intermediários de DEMS em relação aos fenos das mamonas e do feno da maniçoba (Tabela 5). A superioridade da DEMS do feno da mamona Paraguaçu pode ser explicado, em parte, devido a sua maior taxa de fermentação (c) da fração (b). Por outro lado, a menor DEMS do feno da maniçoba pode ser relacionado com o seu menor valor da fração (b).

A degradabilidade efetiva da proteína bruta (DEPB) do feno do pinhão manso foi menor em comparação aos fenos das outras euforbiáceas (Tabela 5). Este resultado pode estar relacionado com a menor fração (a) e com a menor taxa de fermentação (c) da fração (b) da PB desta forragem. $\mathrm{O}$ feno da maniçoba apresentou DEPB maior que a do feno do pinhão manso. Os fenos das mamonas apresentaram os maiores valores de DEPB, a mamona Nordestina foi superior à mamona Paraguaçu (Tabela 5). 
Esta superioridade do feno da mamona Nordestina pode ser explicada, em parte, pelo seu maior conteúdo da fração (a), e pela maior taxa de degradação (c) da fração (b) desta forragem (Tabela 5). Carvalho et al. (2006b) obtiveram valor menor para a DEPB da parte aérea da mandioca $(59,96 \%)$, considerada a taxa de passagem de $5 \%$.

A maior degradabilidade efetiva da fibra em detergente neutro (DEFDN) foi apresentada pelo feno do pinhão manso (Tabela 5). Este resultado pode ser explicado, em parte, devido ao maior valor da fração (b) desta forragem. A menor DEFDN foi apresentada pelo feno da maniçoba, que apesar de ter apresentado a maior taxa de degradação (c) da fração (b), teve o menor valor desta fração. Os fenos das mamonas apresentaram valores intermediários de DEFDN, em relação aos fenos do pinhão manso e da maniçoba (Tabela 5). Ao se considerar a taxa de passagem de 5\%, os valores para a DEFDN obtidos foram superiores ao descrito por Carvalho et al. (2006b) para o feno da parte aérea da mandioca $(19,72 \%)$.

Os fenos das euforbiáceas testados mostraram potencial de utilização na alimentação de ruminantes e os fenos da mamona Nordestina e da mamona Paraguaçu apresentaram-se superiores aos fenos da maniçoba e do pinhão manso em relação às variáveis testadas.

\section{REFERÊNCIAS}

CARVALHO, G.G.P.; PIRES, A.J.V.; VELOSO, C.M.; DETMANN, E.; SILVA, F.F.; SILVA, R.R.

Degradabilidade ruminal do feno de alguns alimentos volumosos para ruminantes. Arquivo Brasileiro de Medicina Veterinária e Zootecnia, v.58, n.4, p.575-580, 2006a.
CARVALHO, G.G.P.; PIRES, A.J.V.; VELOSO, C.M.; SILVA, S.S.; SILVA, R.R. Degradabilidade ruminal do feno de forrageiras tropicais. Revista

Brasileira de Agrociência, v.12, n.1, p.81-85, 2006b.

FRANÇA, A.A.; GUIM, A.; BATISTA, A.M.V.; PIMENTEL, R.M.M.; FERREIRA, G.D.G.; MARTINS, I.D.S.L. Anatomia e cinética de degradação do feno de Manihot glaziovii. Acta Scientiarum Animal Sciences, v.32, n.2, p.131-138, 2010.

FREITAS, S.M.; FREDO, C.E. Biodiesel à base de óleo de mamona: algumas considerações. Informações Econômicas, v.35, n.1, p.37-42, 2005.

GOMES, J.A.F.; LEITE, E.R.; CAVALCANTE, A.C.R.; CÂNDIDO, M.J.D.; LEMPP, B.; BOMFIM, M.A.D.; ROGÉRIO, M.C.P. Resíduo agroindustrial da carnaúba como fonte de volumoso para a terminação de ovinos. Pesquisa Agropecuária Brasileira, v.44, n.1, p.58-67, 2009.

LOUSADA JÚNIOR, J.E.; NEIVA, J.N.M.; RODRIGUEZ, N.M.; PIMENTEL, J.C.M.; LÔBO, R.N.B. Consumo e digestibilidade de subprodutos do processamento de frutas em ovinos. Revista Brasileira de

Zootecnia, v.34, n.2, p.659-669, 2005.

MORAIS, D.A.E.F.; VASCONCELOS, A.M. Alternativas para incrementar a oferta de nutrientes no semi-árido brasileiro. Revista Verde de Agroecologia e Desenvolvimento Sustentável, v.2, n.1, p.1-24, 2007.

NATIONAL RESEARCH COUNCIL NRC. Nutrient requirements of small ruminants. Washinton: National Academy of Sciences, 2007. 362 p. 
ØRSKOV, E.R.; McDONALD, I. The estimation of protein degradability in the rumen from incubation measurements weighted according to rate of passage. Journal of

Agricultural Science, v.92, n.2, p.499503, 1979.

PIRES, A.J.V.; REIS, R.A.; CARVALHO, G.G.P.; SIQUEIRA, G.R.; BERNARDES, T.F.; RUGGIERI, A.C.; ALMEIDA, E.O.; ROTH, M.T.P. Degradabilidade ruminal da matéria seca, da fração fibrosa e da proteína bruta de forrageiras. Pesquisa

Agropecuária Brasileira, v.41, n.4, p.643-648, 2006.

SILVA, D.J.; QUEIROZ, A.C. Análise de alimentos: métodos químicos e biológicos. 2.ed. Viçosa, MG:

Universidade Federal de Viçosa, 2002. $165 \mathrm{p}$.
SILVA, L.D.F.; RAMOS, B.M.O.; RIBEIRO, E.L.A.; MIZUBUTI, I.Y.; ROCHA, M.A.; MORAES, F.L.Z. Degradabilidade ruminal in situ da matéria seca e proteína bruta de duas variedades de grão de soja com diferentes teores de inibidor de tripsina, em bovinos. Revista Brasileira de Zootecnia, v.31, n.3, p.1251-1257, 2002.

SAS INSTITUTE. Statistical analyses system user's guide. Version 9.1. Cary, 2003.

TOMICH, T.R.; GONÇALVES, L.C.; MAURÍCIO, R.M.; PEREIRA, L.G.R.; RODRIGUES, J.A.S. Composição bromatológica e cinética de fermentação ruminal de híbridos de sorgo com capim-sudão. Arquivo Brasileiro de Medicina Veterinária e Zootecnia, v.55, n.6, p.747-755, 2003.

Data de recebimento: $25 / 05 / 2011$

Data de aprovação: 10/02/2012 